\title{
The Growing Semantic Web
}

\author{
Mark Greaves \\ Vulcan Inc., USA
}

\begin{abstract}
From its beginnings in 2004, the data available on the web in Semantic Web formats has typically been both eclectic and relatively small, and closely linked the interests of particular researchers. In the past year, however, the quantity and scope of data published on the public semantic web has exploded, and the size of the semantic web is now measured in the billions of assertions. It is a significant and growing resource for applications which depend on web-based resources for some or all of their knowledge. With this massive increase in quantity and scope come many opportunities, as well as the usual issues of scale on the web: inconsistency, mapping problems, incompleteness and data variability. This talk will cover the history and current state of the Semantic Web and the Linked Data Cloud, describe some of the uses to which webbased semantic data is currently put, and discuss prospects for the ECML/PKDD community to leverage this growing web of data.
\end{abstract}

